\title{
Behaviour of Membrane Construction Materials under Multi-Axial Tensile Loading
}

\author{
S. Chen ${ }^{1, a}$, R. Fangueiro ${ }^{2, b}$, X. Ding ${ }^{3, \mathrm{c}}$ and $\mathrm{H} . \mathrm{Yi}^{4, \mathrm{~d}}$ \\ ${ }^{1}$ College of Textile, Zhongyuan University of Technology, 450007 Zhengzhou, Henan, PR China \\ ${ }^{2}$ Department of Textile Engineering, University of Minho, 4800-058 Guimarães, Portugal \\ ${ }^{3}$ College of Textiles, Donghua University, 200051 Shanghai, PR China \\ ${ }^{4}$ Colleges of Fashion and Art Design, Jiaxing University, 314001 Jiaxing, Zhejiang, PR China \\ aisland0410@gmail.com, ${ }^{b}$ rfang@det.uminho.pt, cxding@dhu.edu.cn, dyi-hl@163.com
}

Keywords: Membrane materials, PVC-coated fabrics, Tensile properties, Multi-axial loading, Crack.

\begin{abstract}
This paper focused on the tensile performance of PVC-coated membrane materials under multi-axial loads. Several groups of experiments were carried out to investigate the effect of the specimen configuration and the loading speed on the tensile properties. It could be concluded that the configuration of the specimen plays an important role on the tensile performance of the materials. The suitable configuration for multi-axial loading tests had been identified. It was also found out that the loading speed had certain effect on the tensile failure performance and the tensile response. A loading speed of lower than $20 \mathrm{~mm} / \mathrm{min}$ was suggested to achieve a reasonable result of the multi-axial tensile performance of PVC-coated membrane materials. Another group of tensile experiments with a crack in the center of the specimens under multi-axial loads were performed. It was noticed that the tensile properties in warp direction of the coated membrane materials play an important role in the tensile failure under multi-axial loads, no matter the initial crack length and the crack orientation are.
\end{abstract}

\section{Introduction}

Lightweight structures such as tension structures and air-supported structures have been applied dramatically in the past thirty years. Coated membrane materials as the roof materials used for this kind of architectures play an important role in the application and the service life. As a kind of flexible materials, coated membrane materials have virtually no bending stiffness, and therefore can only resist in tension. To sustain a shape, the membrane material must be in tension. Mechanical properties in tension are very important to establish the material properties for structural design, installation and maintenance [1].

In the application of the membrane materials for the architectures, the loads are very complicated. In addition to the tension from the structure, the roofing materials will suffer from natural condition, such as temperature, rain, wind or snow, etc. Many literatures [2-6] had focused on the tensile performance of coated membrane materials under uni-axial and bi-axial loads. Due to the lack of multi-axial tensile testing machine, the performance of the coated membrane materials under multi-axial loads has been investigated very little.

This paper focused on the experimental investigation of the tensile performance of the coated membrane materials under multi-axial tensile loads. Since there isn't any standard for the multi-axial tensile testing, the factors, such as the configuration of the specimen and the loading speed, which might affect the testing results were investigated. The tensile performance of the coated membrane materials under different kind of loads (uni-axial, bi-axial and multi-axial) was compared. Finally, the tensile performances of the coated membrane materials under multi-axial tensile loads with a crack in the center were analyzed. 


\section{Experimental}

All of the tensile tests were performed on a multi-axial testing machine - TexTest (shown as Fig. 1) at University of Minho in Portugal [7]. The multi-axial testing machine has four pairs of clamps in the symmetrical directions. Each pair of the clamps, controlled by individual motor, move independently. The original distance between two jaws is $260 \mathrm{~mm}$. In each axis the loading mode is constant rate of extension (CRE). The loading speed is $5 \sim 100 \mathrm{~mm} / \mathrm{min}$. Therefore, the displacement of each pair of the clamps could be calculated automatically according to the loading time and the loading speed.

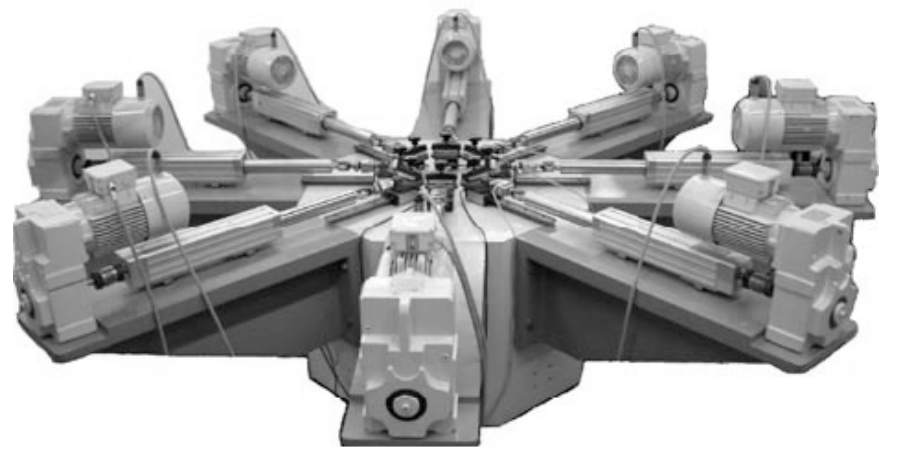

Fig. 1 The multi-axial testing machine.

PVC-coated polyester fabrics with a surface treatment of acrylate were used as the sample of coated membrane materials in the current research.

To identify the configuration of the specimens for multi-axial tensile tests, a group of experiments was carried out with four types of configurations (see in Fig. 2). These configurations were designed according to the experience of the experiments of tensile loading test for coated woven fabrics under bi-axial loads [2, 8-10]. To see the distribution of the stress under multi-axial tensile loads, series of homocentric rounds were drawn on the surface of the specimens. The loading speed was $5 \mathrm{~mm} / \mathrm{min}$. After the configuration of the specimen was identified, a second group of experiments was performed to see if there is a great influence of the loading speed $(v=5,20,50$ and $100 \mathrm{~mm} / \mathrm{min})$ on the tensile performance under multi-axial tensile loads.

Another group of experiments was performed on the specimens with a crack in the center to investigate the tearing performance of the coated membrane materials under multi-axial tensile loads. Three levels of the initial crack length $(2 \mathrm{a}=20,40$ and $60 \mathrm{~mm})$ and five levels of the initial crack orientation to the warp direction of materials $\left(\theta=0^{\circ}, 22.5^{\circ}, 45^{\circ}, 67.5^{\circ}\right.$ and $\left.90^{\circ}\right)$ were involved. The loading speed was $5 \mathrm{~mm} / \mathrm{min}$ in all axes. For all of the experiments mentioned above, the principle directions (warp and weft directions) of the coated membrane material were paralleled with the axis 1 and the axis 3, respectively. For each test, two or three specimens were tested.

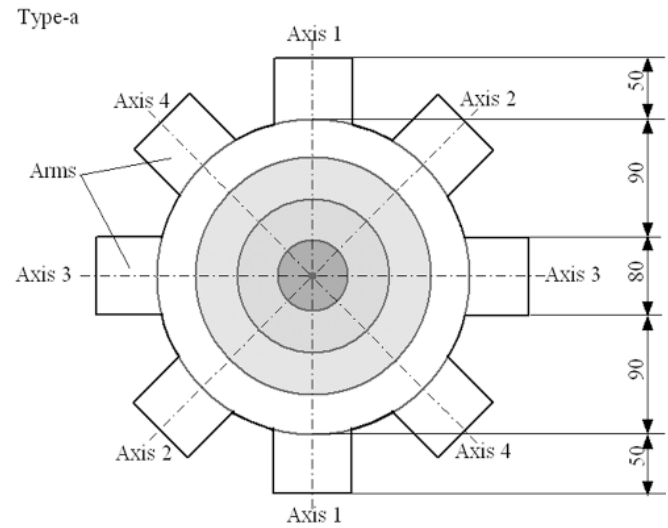

(a) type-A

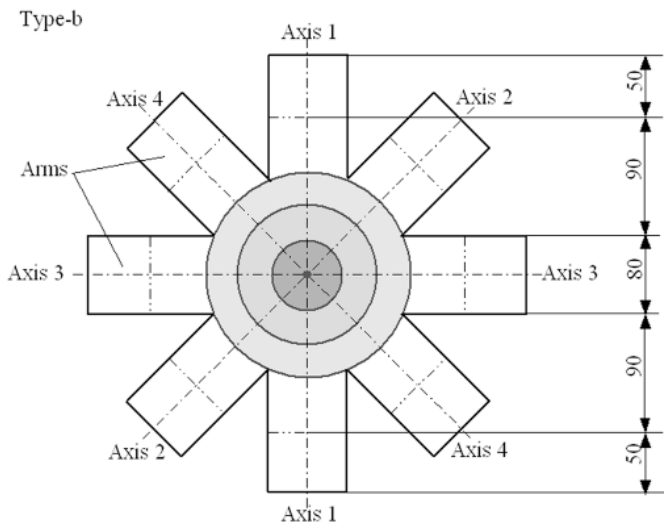

(b) type-B

Fig.2. Configurations (type A and type B) of the specimens for multi-axial tensile tests (dimensions in $\mathrm{mm}$ ). 


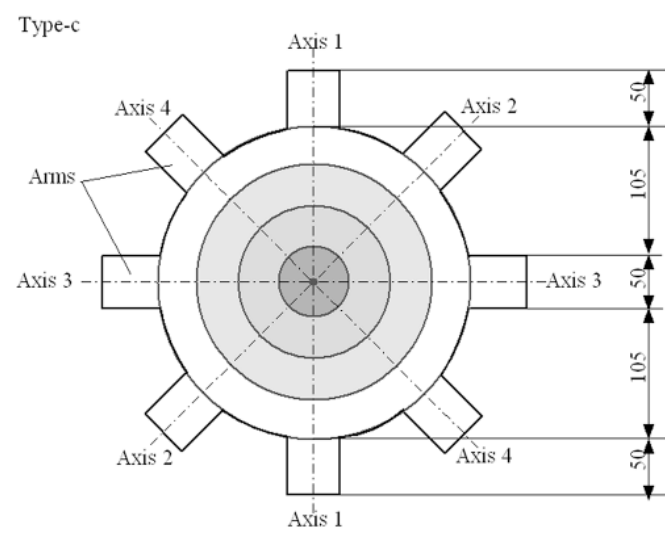

(c) type-C

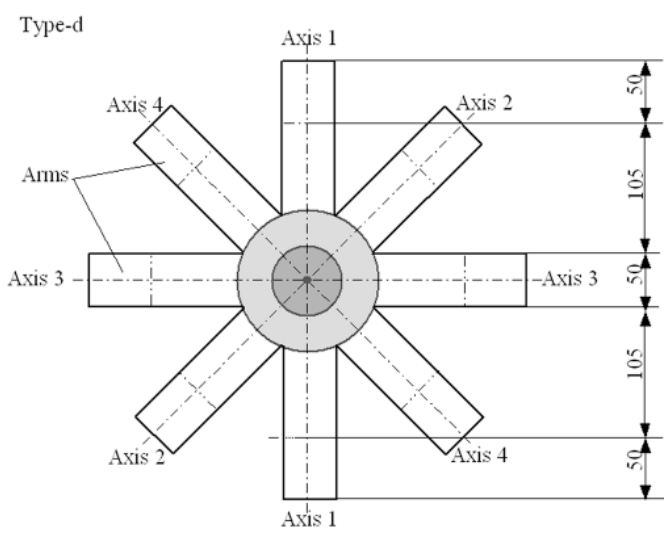

(d) type-D

Fig. 2 (cont.). Configurations (type $\mathrm{C}$ and type $\mathrm{D}$ ) of the specimens for multi-axial tensile tests (dimensions in $\mathrm{mm}$ ).

\section{Results and Discussions}

The Identification of the Specimen Configuration. The stress distribution under multi-axial tensile loads on specimens with four types of configurations is shown in Fig. 3. It shows that on the specimens with a larger width (80mm) (in type-A and type-B) for clamping, the stress distribution along the four loading directions is much more uniform than that with a smaller width $(50 \mathrm{~mm})$ (in type-C and type-D).

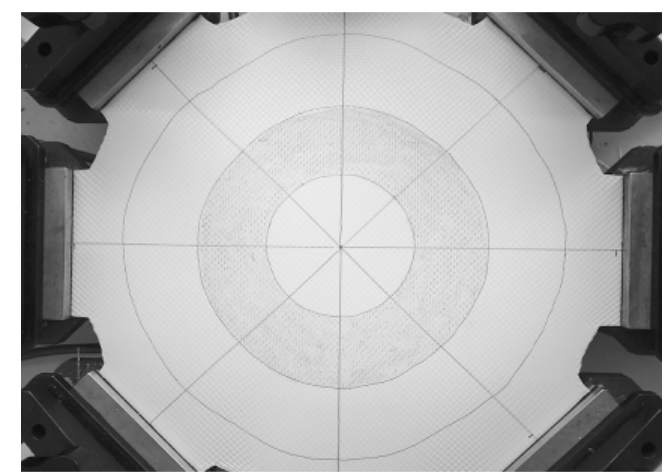

(a) type-A

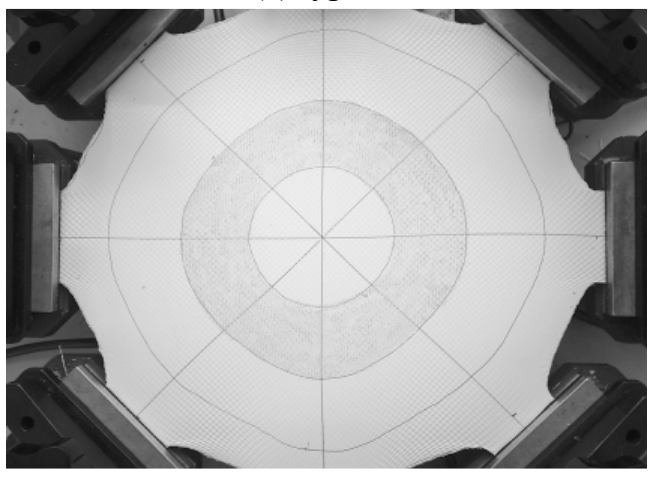

(c) type-C

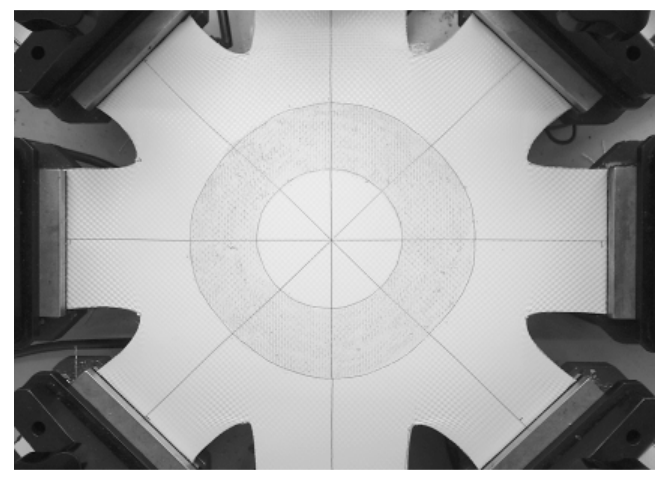

(b) type-B

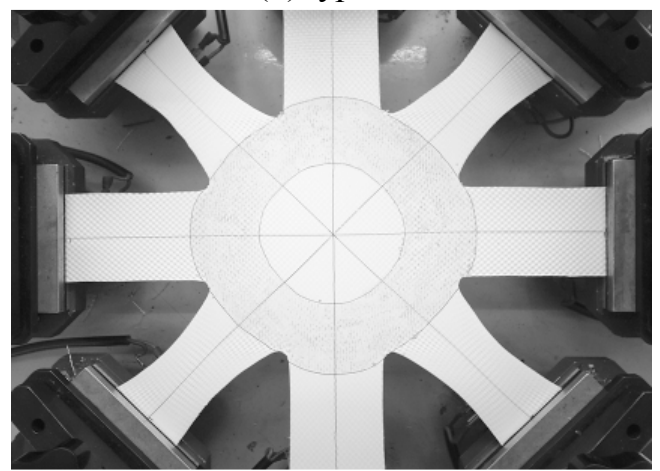

(d) type-D

Fig. 3. The stress distribution under multi-axial tensile loads.

Figure 4 shows the tensile response under multi-axial loads on the specimens with different configurations. From Fig. 4 , it can be noticed that the tensile modulus in axis 2 or in axis $4\left(45^{\circ}\right.$ direction) on the specimens of type-A and type- $\mathrm{C}$ is much higher than that on the specimens of type-B and type-D. This phenomena results from that on the specimens of the type-B and type-D the 
multi-axial tensile response in axis 2 or in axis 4 ( $45^{\circ}$ direction) depends mainly on the uni-axial tensile response of the coated material in $45^{\circ}$ direction due to the existence of the long loading arms. The interaction effect of the four loading directions in specimens of type-B and type-D is less than that in specimens of type-A and type-C. Therefore, experiments on specimens of type-B and type-D can not give an almost real response when the specimens suffering from multi-axial tensile loads, since the interaction effect between the four loading directions have been eliminated dramatically.

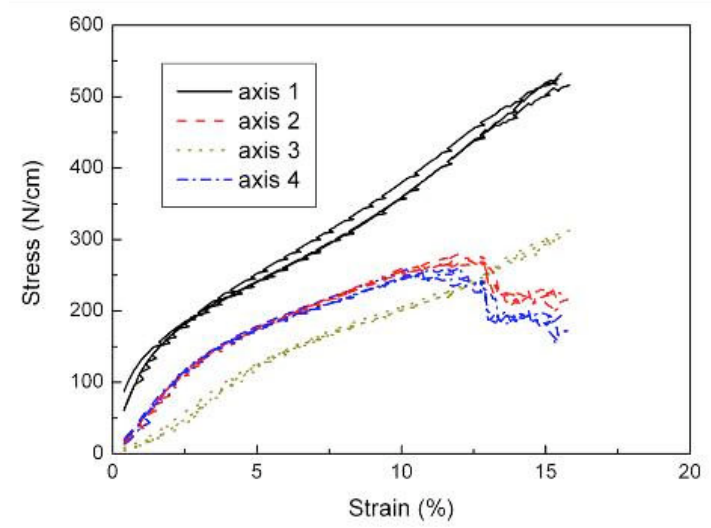

(a) type-A

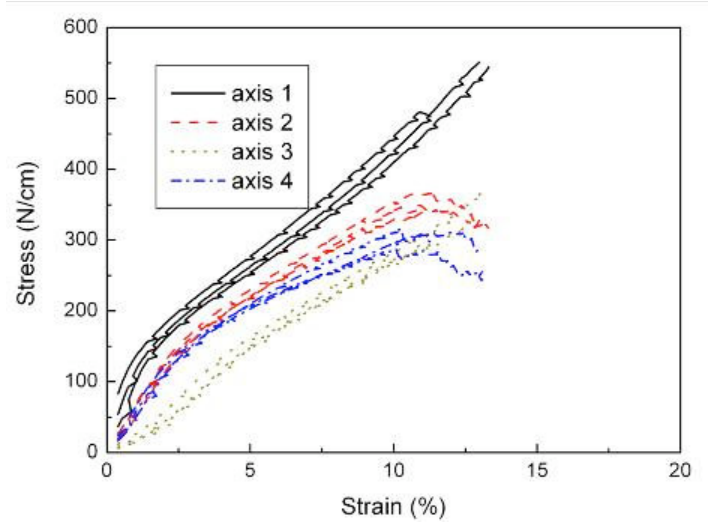

(c) type-C

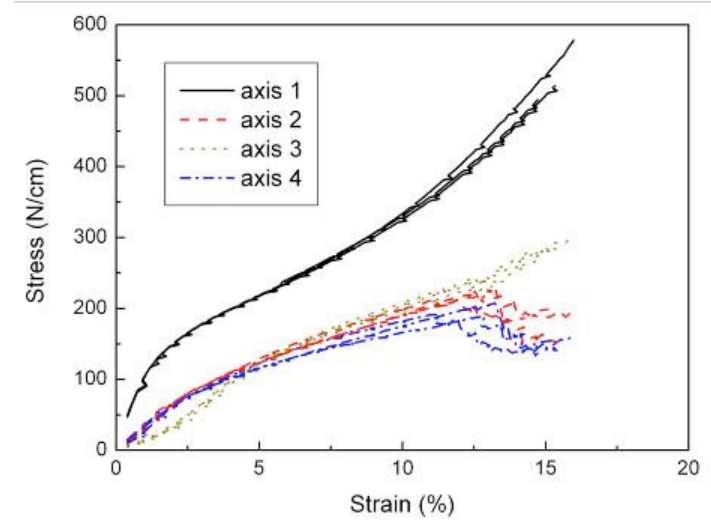

(b) type-B

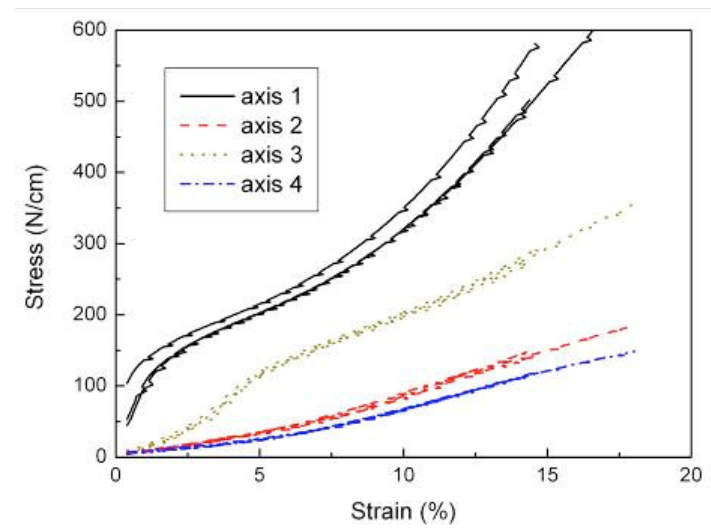

(d) type-D

Fig. 4. The multi-axial tensile response.

In conclusion, to achieve a real response of coated membrane materials under multi-axial tensile loads, the configuration of type-A is much better than the others. In the following investigation, only the specimens with a configuration of type-A were used.

The Identification of the Loading Speed. The tensile performances under multi-axial loads are affected dramatically by the loading speed (see Fig. 5).The dispersion of the experiments at a lower speed $(5 \mathrm{~mm} / \mathrm{min}$ and $20 \mathrm{~mm} / \mathrm{min})$ is less than that at a higher loading speed $(50 \mathrm{~mm} / \mathrm{min}$ and $100 \mathrm{~mm} / \mathrm{min}$ ). Besides, the non-linear tensile response of the materials in each axis at lower stress has been neglected when loading at a higher speed of $100 \mathrm{~mm} / \mathrm{min}$. The true tensile response can only be obtained at a lower loading speed $(v \leq 20 \mathrm{~mm} / \mathrm{min})$. From Fig. 5 , it can be found that with the increase of loading speed, the tensile strength in axis 1 (warp direction) decreases obviously and the elongation at break declines dramatically. Therefore, in the following multi-axial experiments, a loading speed of $5 \mathrm{~mm} / \mathrm{min}$ is employed. 


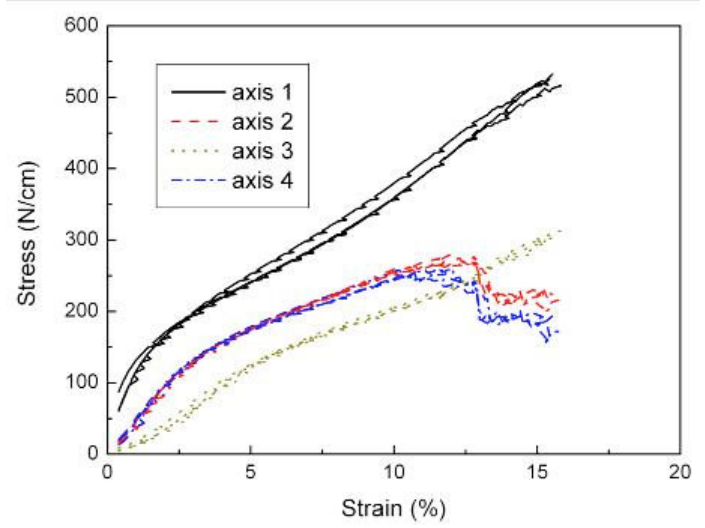

(a) $5 \mathrm{~mm} / \mathrm{min}$

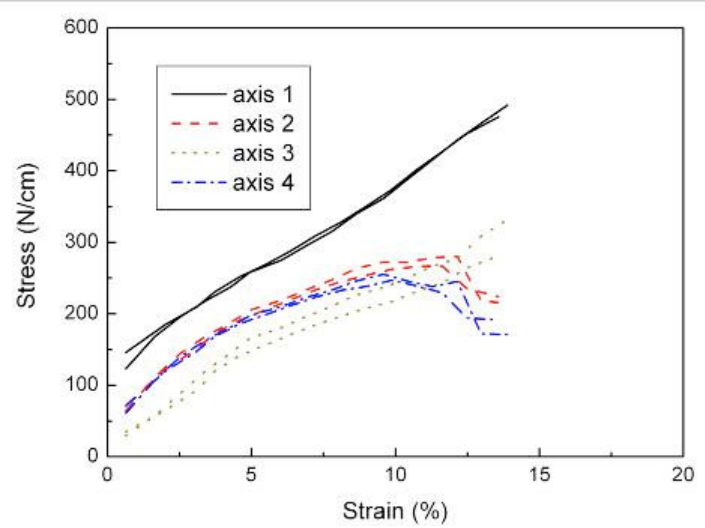

(c) $50 \mathrm{~mm} / \mathrm{min}$

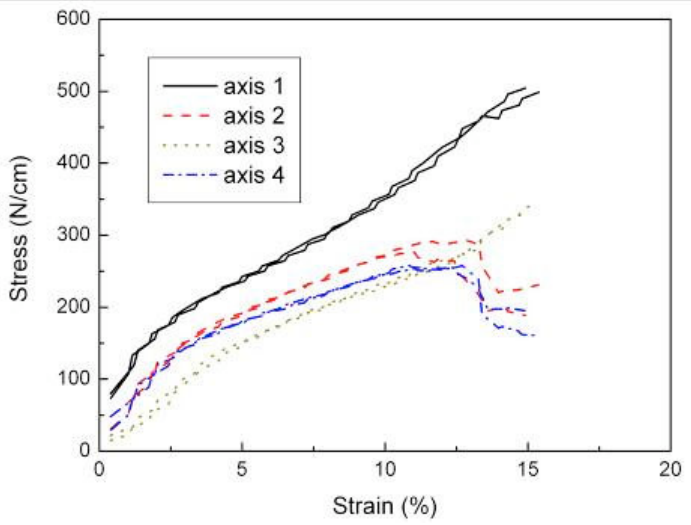

(b) $20 \mathrm{~mm} / \mathrm{min}$

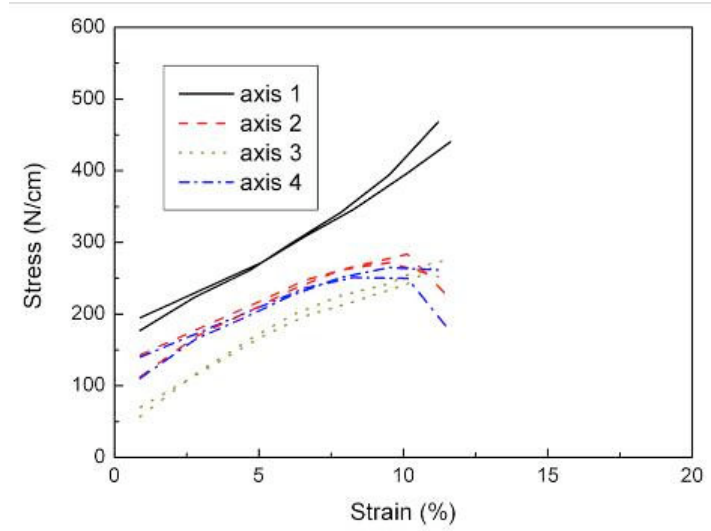

(d) $100 \mathrm{~mm} / \mathrm{min}$

Fig. 5. The multi-axial tensile response at different loading speed.

\section{The Tensile Failure Performance with a Crack}

Under multi-axial tensile loads, due to the tensile anisotropy of coated membrane materials, the propagation strengths in each loading axis of the specimens without crack are different (see in Fig. 4). The strength (about $525 \mathrm{~N} / \mathrm{cm}$ ) in axis 1 (warp direction) is much stronger than that in other axes. When there is a crack in the center of the specimens, the propagation threshold (for progressive failure) or the failure strength (for brutal failure) in axis 1 (warp direction) drops more dramatically than that in the other axes (in weft and $45^{\circ}$ directions) as the initial crack length and the crack orientation increase (see in Fig. 6). In the axis 2 or axis 4 ( $45^{\circ}$ direction), the effect of the initial crack length and the crack orientation on the maximum strength can be neglected thoroughly. This shows that the mechanical properties in warp direction of the coated membrane materials play an important role in the tensile failure under multi-axial loads, whatever the initial crack length and the crack orientation is.

From Fig. 7 it can be found that with the increase of the crack orientation, the elongation at break decreases. Besides, the initial crack length has almost no effect on the elongation at break. As the crack orientation increase from $0^{\circ}$ to $90^{\circ}$, the trend of the decrease of the elongation at break accords with the decrease of the maximum strength in warp direction. This emphasizes the importance of the tensile properties in warp direction when the coated membrane materials are suffering from multi-axial tensile loads. 


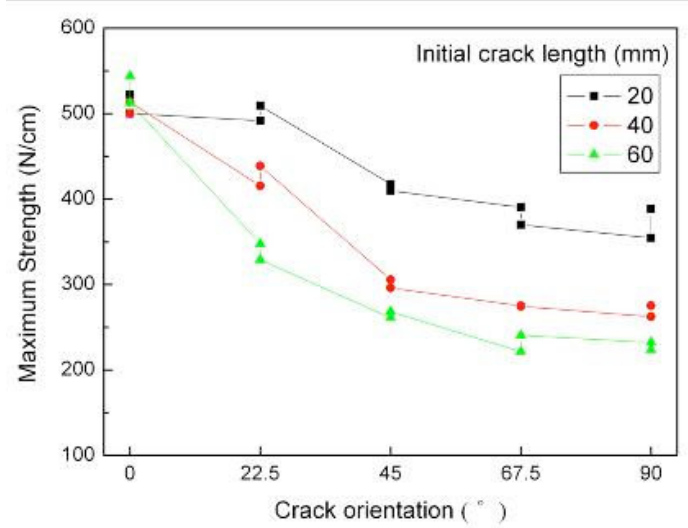

(a) in axis $1=$ warp direction

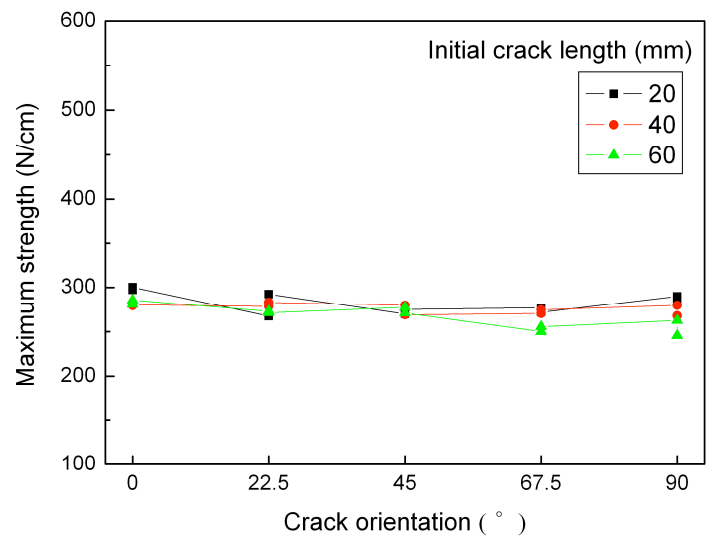

(b) in axis $3=$ weft direction

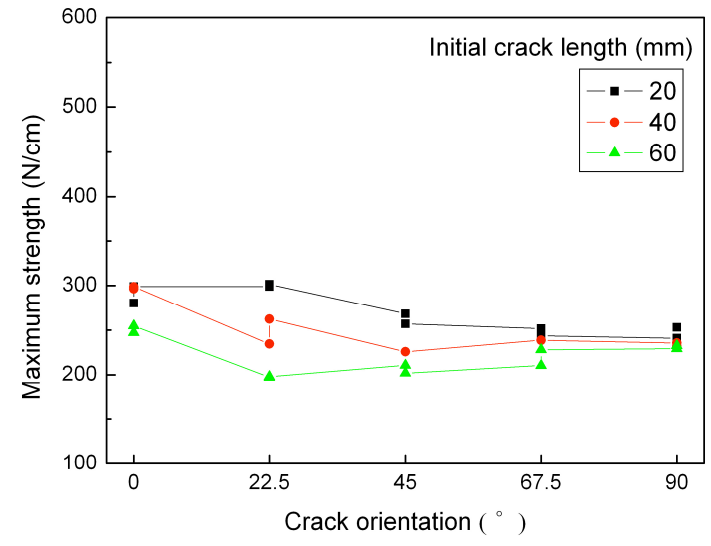

(c) in axis 2 or $4=45^{\circ}$ direction

Fig. 6. The effect of the crack on the maximum strength.

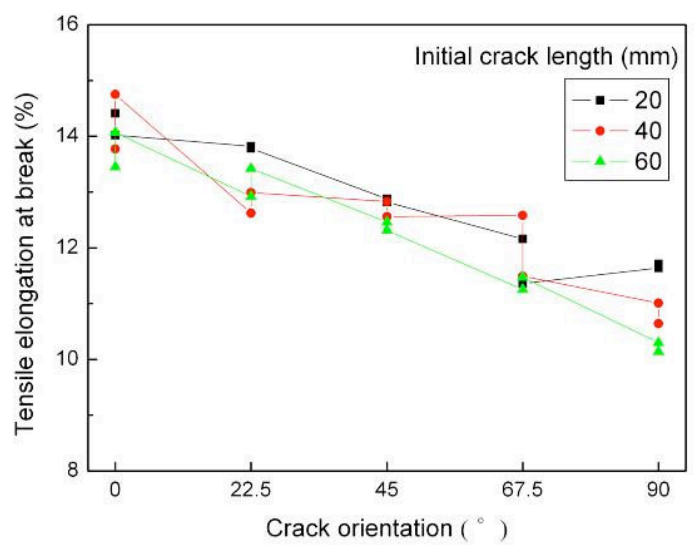

Fig. 7. The effect of the crack on the elongation at break.

From the failure images of the coated material with a crack in the center under multi-axial loads, it could be found that the crack propagation or the failure (brutal or progressive) happens always in the warp direction even though when the crack is $0^{\circ}$ orientation with the initial length of $60 \mathrm{~mm}$, the crack propagation happens in weft direction and the failure is still in the warp direction. However, according to the work of Bigaud [11], under bi-axial loads, the failure (brutal or progressive) happens in the warp or in the weft direction depending on the crack orientation and the loading ratios of the two directions applied. This shows that under multi-axial loads due to the same of CRE loading mode in each direction, the failure tends to happen in the direction with a higher modulus - the warp direction of the materials. 
Since the warp direction of the materials is dominating the failure with a crack in the center under multi-axial loads. The failure mode in warp direction is much more important than other directions for the failure of the whole materials under multi-axial loads. Figure 8 shows the failure modes in warp direction with different crack orientations and initial crack lengths. As the initial crack length increases, the failure mode in warp direction (from $20 \mathrm{~mm}$ to $60 \mathrm{~mm}$ ) is developing into the progressive failure from brutal failure, except when the crack orientation is $0^{\circ}$ (along the warp direction). This trend of the failure mode development under multi-axial loads consists with that under bi-axial loads.

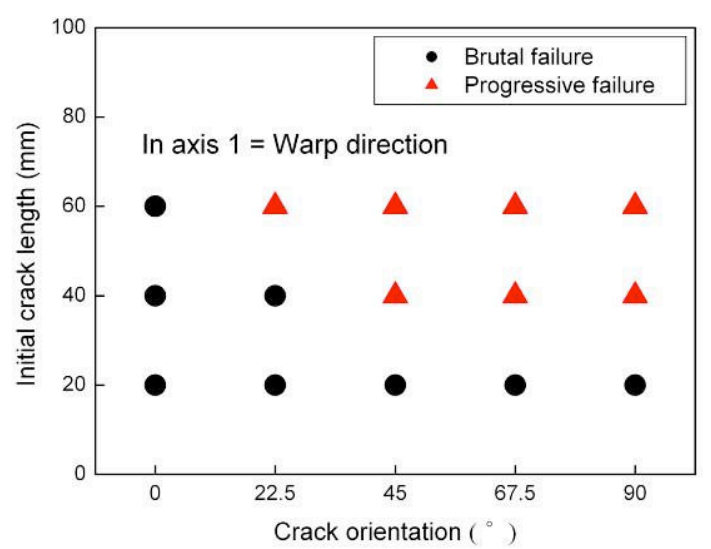

Fig. 8. Multi-axial tensile failure modes according to the initial crack length and crack orientation.

\section{Conclusion}

The items that might affect the tensile experiments of PVC-coated fabrics under multi-axial loads have been investigated. The configuration of the specimen plays an important role on the tensile performance of the materials. With a configuration of Type-A (see Fig. 2), the real tensile performance under multi-axial loads could be achieved. The loading speed has certain effect on the tensile failure performance and the tensile response. When performing multi-axial tensile tests on coated membrane materials, a loading speed of lower than $20 \mathrm{~mm} / \mathrm{min}$ is suggested.

Based on the analysis on the experimental results with a crack in the center of the specimens under multi-axial loads, it was found that the tensile properties in warp direction of the coated membrane materials play an important role in the tensile failure under multi-axial loads, whatever the initial crack length and the crack orientation are.

\section{Acknowledgements}

This study is supported by the European Asia-Link Research Project (2004-2007). Express our grateful acknowledgement to Endutex-Revestimentos Têxteis S.A. in Portugal for the PVC-coated membrane materials provided.

\section{References}

[1] B. N. Bridgens, P. D. Gosling, M. J. S. Birchall: The Structural Engineer Vol. 82 (2004), p. 21-27.

[2] S. H. Chen, X. Ding, R. Fangueiro, H. L. Yi, J. Ni: Journal of Applied Polymer Science Vol. 107 (2008), p. 2038-2044.

[3] S. H. Chen, X. Ding, H. L. Yi: Textile Research Journal Vol. 77 (2007), p. 369-374.

[4] C. Szostkiewicz, P. Hamelin: Journal of Industrial Textiles Vol. 30 (2000), p. 128-145.

[5] H. Minami, S. Motobayashi: Journal of Coated Fabrics Vol. 11 (1981), p. 24-40. 
[6] G. Menges, B. Meffert: Kunststoffe Vol. 66 (1976), p. 741-745.

[7] University of Minho, Patent No. 103034 Portugal (2003).

[8] B. N. Bridgens, P. D. Gosling, M. J. S. Birchall: The Structural Engineer Vol. 82 (2004), p. 28-33.

[9] R. J. Bassett, R. Postle, N. Pan: Polymer Composites Vol. 20 (1999), p. 305-313.

[10]R. Mott, G. Huber, A. Leewood: Journal of Testing and Evaluation Vol. 13 (1985), p. 9-16.

[11]D. Bigaud, C. Szostkiewicz, P. Hamelin: Composite Structures Vol. 62 (2003), p. 129-137. 